\title{
CROSS-HOLE GEOTOMOGRAPHY IN A PARTIALLY DEPLETED RESERVOIR
}

\author{
Progress Report \\ March 1991 \\ Principal Investigator \\ J.A. McDonald \\ Houston Petroleum Research Center \\ University of Houston \\ Houston, TX 77204-4231
}

\section{PREPARED FOR THE U.S. DEPARTMENT OF ENERGY UNDER GRANT NUMBER DE-FG05-89ER 14058}

\author{
DISCLAIMER
}

\begin{abstract}
This report was prepared as an account of work sponsored by an agency of the United States Government. Neither the United States Government nor any agency thereof, nor any of their employees, makes any warranty, express or implied, or assumes any legal liability or responsibility for the accuracy, completeness, or usefulness of any information, apparatus, product, or process disclosed, or represents that its use would not infringe privately owned rights. Reference herein to any specific commercial product, process, or service by trade name, trademark. manufacturer, or otherwise does not necessarily constitute or imply its endorsement, recommendation, or favoring by the United States Guvernment or any agency thereof. The views and opinions of authors expressed herein do not necessarily state or reflect those of the United States Government or any agency thereof.
\end{abstract}


Although the project was originally funded in August 1989 research was not initiated until the Spring of 1990 (see Progress Report dated: April 1990). Research has continued in the second year of this project essentially under four headings. These four headings are; a) Geological Description of the West 76 Field (under the direction of D.S. Hamilton. Bureau of Economic Geology). b) Cross-Hole Data Acquisition (C.A. Link), c) Cross-Hole Data Analysis (H.W. Zhou) and, d) Reprocessing of CDP data (D.A. Ebrom), to target the Frio \& Cole sands in the 76 Field.

The geological investigations cover all of the shallow production in the field but the cross-hole measurements are now targetted at the shallower Frio sands, as described below.

\section{a) Geological Description}

Initial experiments were aimed at the productive Jackson-Yegua sands but subsequent experiments have been directed at the shallower Frio sands. We have also concentrated on Section 62 in the field. Experiments targeted a Frio Sandstone that occurs in the eastern half of the Seventy-Six West Field.. Although non-productive in this field. Frio sandstones are prolific producers along the Test Gulf Coast. The Frio sandstone at SeventySix West is up to $40 \mathrm{ft}$ thick and was deposited in narrow, dip-oriented mixed-load to bed-load fluvial channels. Sandstone isopachs lllustrate a strongly developed tributary pattern reflecting migration of the channels across a gently sloping, muddy floodbasin. Sandstone thickness between the experimental wells 62-7, 62-9, and 62-19 ranges from 17-26 ft, and the trend of the sandstone at this location defines the edge of a meander-loop. The experimental site is thus favorably located to model lateral accretion elements associated with channel migration as well as the complex internal architecture of the channel-fill. Petrophysical characteristics of the Frio sandstone such as sediment composition and degree of cementation and compaction are probably comparable to those of the Cole sandstones in the underlying Jackson Group. The initial experiments on the Frio sandstone will therefore, be directly applicable to subsequent experiments on the oilproductive Cole sandstones.

\section{b) Cross-hole Data Acquisition}

At present. three sets of field experiments have been conducted in the West 76 field in Duval County. The goal of the third set of field experiments was to determine the most suitable downhole source for collecting a complete tomogram. Four sources were tested:

1) a water gun,

2) an air gun.

3) an arc discharge tool, and

4 ) the cylindrical bender. 
Fan data were to be collected from each of the sources and analyzed to determine the best source in terms of parameters such as:

- energy propagated at various offsets.

- variation of energy propagation with radiation angle.

- tool reliability.

- length of time required to collect a data set.

- signal to noise ratio.

- cost of required supporting equipment.

The signal strength of the water gun was expected to lie between that of the air gun and the output from the arc discharge tool. However, no data were collected using the water gun because the tool would not fire correctly. Use of the water gun as a possible source could not be evaluated but is unlikely for use as a source because of mechanical considerations.

Data collected from the air gun consist of a set of horizontal shots and three "fans". The airgun also experienced mechanical difficulties. Transducers attached to the gun to determine the time break performed erratically and finally failed before the last fan could be completed. Other problems included failure of the main O-rings in the tool, occasional misfires, and problems with the synching communication. The air gun had been used successfully in previous experiments but is probably not optimum for the following reasons:

- It may possibly cause damage to the borehole.

- Although it has a high energy output. its frequency content is low.

- The mechanical reliability of the tool is erratic.

- The accompanying tube wave is high in amplitude.

The arc discharge tool is an impulsive source which utilizes the discharge of a high voltage capacitor through salt water. Energy output of the sparker is estimated to be considerably less than that of the air gun but more than that of the cylindrical bender. Data sets consisting of five fans were collected. Numerous mechanical problems occurred while using the sparker. Fallure of the main power supply prevented data collection at the $600 \mathrm{ft}$ offset. Data analysis shows that the time break cannot be determined with confidence. The sparker is a potentially good source for a field such as West 76. The main problem with the current configuration is its unreliability.

The cylindrical bender is a reliable tool capabie of outputting a variable signal or sweep. Output energy levels are low requiring a high stack number to create a usable signal. The advantage of this tool is the ability to input a variable signal. Data processing can be performed by correlating the data with the input sweep. In addition, the large stack number will greatly diminish random noise. Data were collected at offsets of $200 \mathrm{ft}$. and $600 \mathrm{ft}$. Data quality at the $200 \mathrm{ft}$. offset is very good for both burst and sweep data. 
Data quality at the $600 \mathrm{ft}$ offset indicates that sweep data with associated processing will give best results.

The cylindrical bender appears to be the best candidate for a reliable. high frequency content source. Data processing indicates generated sweeps provide a means of obtaining a usable signal to noise ratio at long offsets. Drawbacks for the bender are its low energy output and the amount of time required for the large numbers of sweeps at longer offsets. Advantages include reliability, controlled frequency input, and operational efficiency.

\section{c) Crose-Eole Data Anatyads}

Since last summer, we have been developing and simulating a number of analysis algorithms on a SUN and on a new CONVEX C210 computer. Firstly, we have implemented and improved an acoustlic ray tracing method which meets the requirements of physical soundness, reliability, and speed. Secondly, we have been pursuing better ways in phase arrival identification. Our studies show that random amplitude noise can be greatly suppressed using bandpass filtering, taking the advantage of the known source frequency content. A combined use of the waveform envelope and the variation of high order moments will be a viable mean to correct the random phase shifts. Thirdly, we have explored an iterattve direct inversion approach aiming to handle a fundamental difficulty of the coupling between the velocities to be imaged and the raypaths used by inversion. Two types of direct inversion algorithms have been implemented using the singular value decomposition and the conjugate gradient method. We have devised a spatial-coherency filtering algorithm which, based on the connection level of ptxels of similar values, suppresses singular artifacts on a tomogram. Inversion simulations have so far has shown encouraging results. For instance, we found stacking of images from different iterations seems to stabilize true anomalies and reduce the artifacts. We also learn that the use of both low and high frequency energy sources will enhance the reliability of the tomogram and, subsequently, we started trying the idea in the data acquisition using a swept frequency source. The simulations also indicate a major improvement in image quality if we can gather signals at surface geophones between the boreholes. This is because a major increase in data kernel quality.

\section{d) Reprocessing of CDP Data}

We are reprocessing four vibrosels lines which were gathered either over or near to section 62 in the West 76 Field. These data are late 1970s vintage and were gathered for imaging of the deeper section. We are attempting to improve the resolution of the shallower data in hopes of imaging the Cole sands in the Jackson-Yegua group and possibly the Frio sands. 

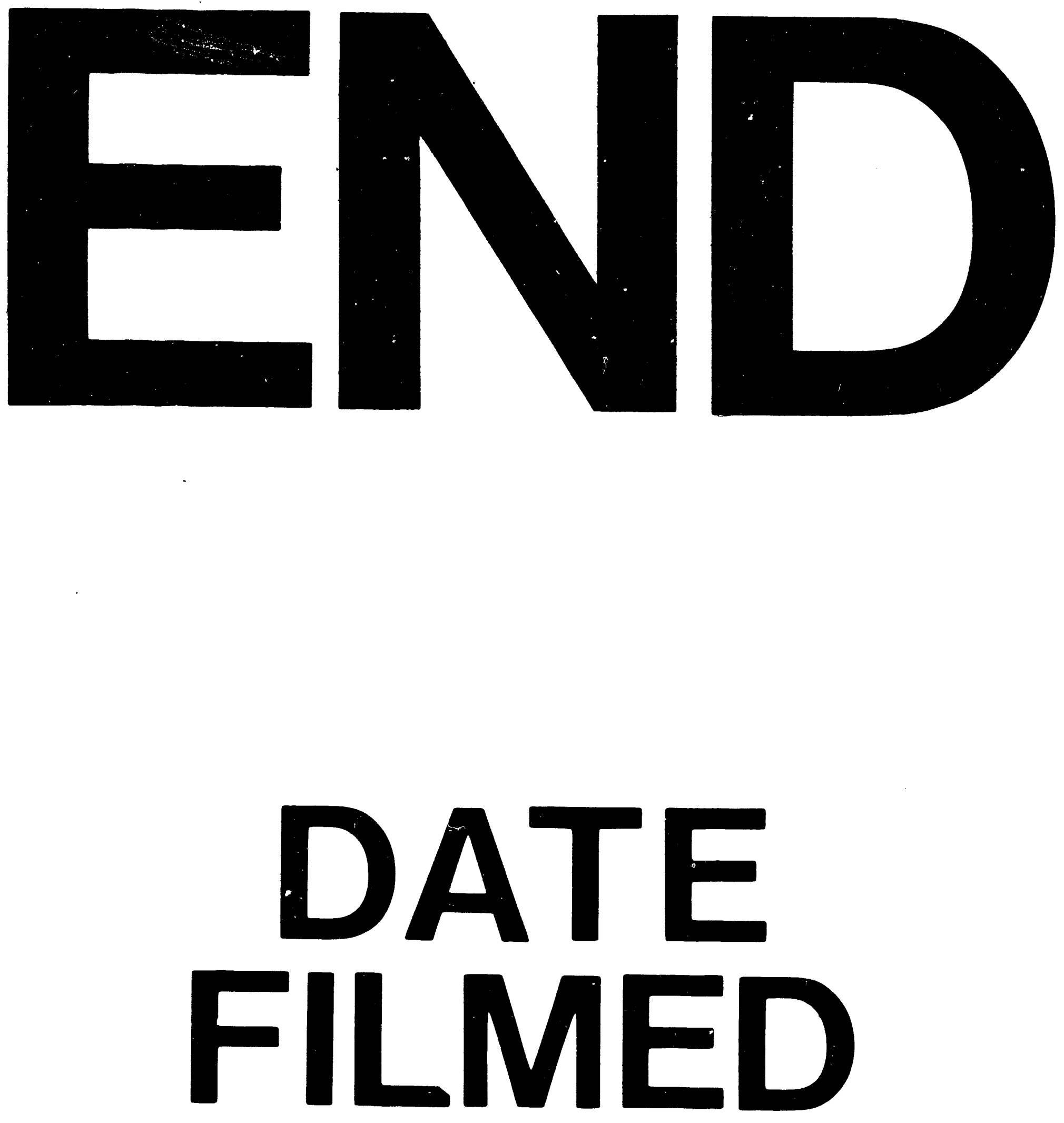

1

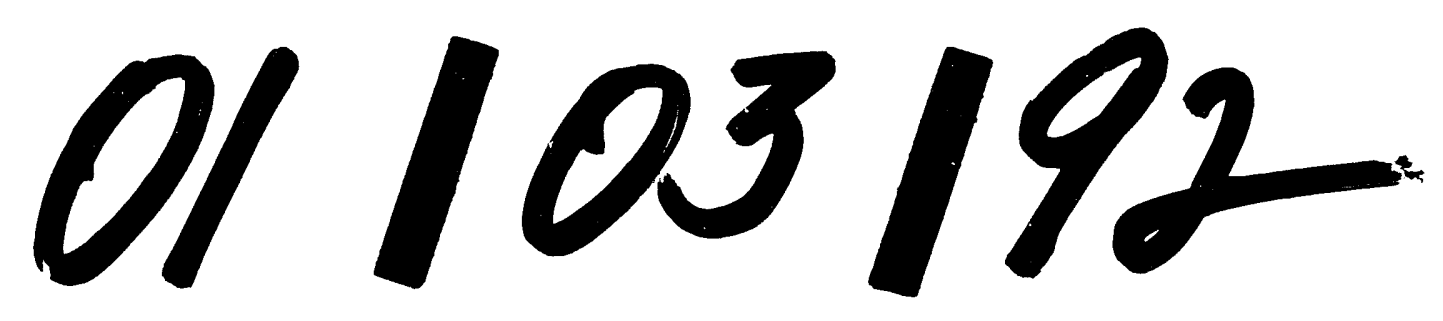


